\title{
On the Changes in Intermediate Metabolism of the Blood Protein and Water by Muscular Exercise in Malnutrition.
}

\author{
By
}

Satoshi Sato.

(佐 藤 哲)

(The Internal Section of Sendai National Hospital.

Director: Dr. T. Kato.)

(Received for publication, September 22, 1949)

It has already been pointed out by a number of investigators, that there occurs in malnutrition apparent hypoproteinaemia accompanied by shift of blood protein fractions, which is closely related to oedema, one of the principal symptoms of this disease. The ultimate cause of the hypoproteinæmia is attributable to deficiency of protein supply. But the blood protein is directly controlled by some special regulating organs. It has been confirmed already by Takizawa ${ }^{1 /}$ and other investigators in autopsy, that there are severe atrophy and degeneration in the leading organs for blood protein regulation, such as liver, spleen, kidney, ductless glands etc., and in the liver obvious disturbances of its various partial functions have been proved. Fuse ${ }^{2}$ has also suggested that there may be causal relation between functional disturbances of liver and decrease of blood protein in this disease. The same could be said on the other blood protein regulating organs: Now we suppose, that the disturbed blood protein regulating function of these organs, which is caused secondarily by deficiency of protein in the body, leads to hypoproteinaemia, which augments again the abnormality of the organ function, so that there exists a circulus vitiosus $\mathrm{cf}$ its own.

Liver and ather several blood preotin regulating organs take in from circulating blood protein particles of albumin class, giving off those of globulin class in $\mathrm{it}^{3-5}$ ), while skeletal muscles release at the time of their contraction usually a lot of albumin in the circulating blood. ${ }^{6)}$ In case of emergency, such as acute anæmia and fasting, the liver may release albumin sometimes though scanty as it is. ${ }^{718}$ In various cases of disturbed liver function albumin in blood uses to decrease and globulin to increase on the contrary, resulting in the decrease of blood protein on the whole ${ }^{9-16)}$, but in case of extremely severe injuries there is ascertained increase of albumin together with diminution of globulin. ${ }^{17-19)}$ 
Now, it is reasonable to comprehend the hypoproteinaemia in malnutrition in connection with injuerd blood protein regulating function of these organs. Nishiyama ${ }^{20}$ observed in healthy man after muscular exercise obvious increase of bload proten concentration and of colloid osmotic pressure of blood, in which the pressure per $1 \%$ protein is also raised. He noticed further, that the rate of increase of the blood pratein concentration is much greater than that of blood haemoglobin concentration. Based on these facts, he concluded that the increase of blood protein concentration by muscular exercise is caused mainly to mobilisation of blood protein, especially that of albumin from protein depot organs in addition to concentrating of blood. Miyamoto and Sugimato ${ }^{21}$ ) confirmed in diseases of extrapyramidal motor system, that the blood albumin increases by muscular exercise remarkably greater than that in healthy man. They attributed it to the abnormality of blood protein regulating center in the brain and functional disturbance of the liver in those diseases.

In malnutrition also, the functions of the organ systems in the body, though more or less injured, maintain a labil equilibrium each other under delicate accommodation, but under some forced loading this incomplete equilibrium is easily broken and the latent functional disturbance becomes manifest. For example it is a well known fact that in our patients the rate of energy consumption is augmented by loading with muscular exercise in much greater extent than in healthy subject, sometimes leading to sudden death by acute insufficiency of blood circulation. It is of great interest to investigate, what kind of changes will be seen in. the blood protein by muscular exercise in this disease, in which the function of the blood protein regulating organs and the blood protein picture itself have been proved as abnormal. From this view-point a certain muscular exercise was given to malnutrition patients and the changes occuring in the blood protein were observed.

Method of Experiments:-12 malnutrition patients entered in our hospital were selected as examinees, who developed the typical symptoms, namely oedema gauntness, depilation, anaemia, polyuria, pollakiuria and hypoproteinæmia, etc., patients having complications such as beri-beri being carefully excluded, The examinees were layed on bed at least 30 minutes early in the morning, when the stomach was empty, then blood samples were taken from the cubital veins, The muscular exercise was given immediately afterward, namely "standing running " at a pace of 150 steps per minutes, lasting for 5 minutes. Bloods were taken in the same way immediately after muscular exercise, after 30 minutes, after 60 minutes and after 90 minutes. The blood protein concentration (\%), the colloid osmotic pressure $\left(\mathrm{mm} \mathrm{H}_{2} \mathrm{O}\right)$, and the haemoglobin concentration $(\mathrm{mg} / \mathrm{dl})$ in each blood sample were estimated. Further, for the purpose of in- 
ferring the ratio of albumin to globulin in the blood the colloid osmotic pressure per $1 \%$ of protein (per \% pressure) was calculated. Blood protein was measured with Pulfrich's immersion refractometer, colloid osmotic pressure by KroghNakazawa's method, haemoglobin concentration with Fleischl-Miescher's haemoglobinometer.

\section{EXPERIMENTAL.}

Results of Experimental.

(I) The control experiments with muscular exercise on the healthy man. (Fig. 1)

On 15 healthy men, chosen as control examinees, the same muscular exercise as for the malnutrition patients was given and the blood samples drawn in the same way were examined. The original values before muscular exercise on an average of 15 cases are as follows: blood protein $7.9 \%$, colloid osmotic pressure $370 \mathrm{~mm} \mathrm{H}_{2} \mathrm{O}$, colloid osmotic pressure per $\%$ protein (per \% pressure) 47 , hæmoglobin concentration $14.0 \mathrm{~mm} / \mathrm{dl}$. Immediately after muscular exercise the blood protein content increases on an average $6.1 \%$, per $\%$ pressure $2.1 \%$, hæmoglobin concentration $5.7 \%$ of each original value. After 30 minutes all values show on the contrary decrease, after 60 or 90 minutes returning in general to the original level.

The fact that the increase of bload protein content is a little greater than that of hæmoglobin concentration in these experiments was recognized in the similar experiments of Nishiyama ${ }^{20)}$ and Miyamoto ${ }^{9)}$; it signifies an increase of the absolute quantity of protein in the blood. Since furthermore, the simultaneous increase of per \% pressure means increase of the ratio of albumin to globulin in the blood protein, it is apparent that the absolute amount of albumin in the blood is also augmented.

(2) Experiments with muscular exercise on the malnutrition patients. (Fig. 2)

The patients investigated in the experiments belonged to the middle degree of this disease, and used to complain of general fatigue, especially feeling of stiffness in the leg from 2 or 3 minutes after beginning of running. In one case the patient complained moreover so severe feeling of oppresion in the chest, dyspnoea and general fatigue, that he fell down on the bed when the exercise finished.

The original values before the muscular exercise are on an average as follows: blood protein content $6.9 \%$, colloid osmotic pressure $269 \mathrm{~mm}$ $\mathrm{H}_{2} \mathrm{O}$, per $1 \%$ pressure 39.0 , hæmoglobin concentration $9.7 \mathrm{mg} / \mathrm{dl}$. The changes in these values after muscular exercise show peculiar curves compared with those of control experiments.

Haemoglobin: The change in haemoglobin concentration im- 
Fig. 1. Average values of 15 healthy examinees.

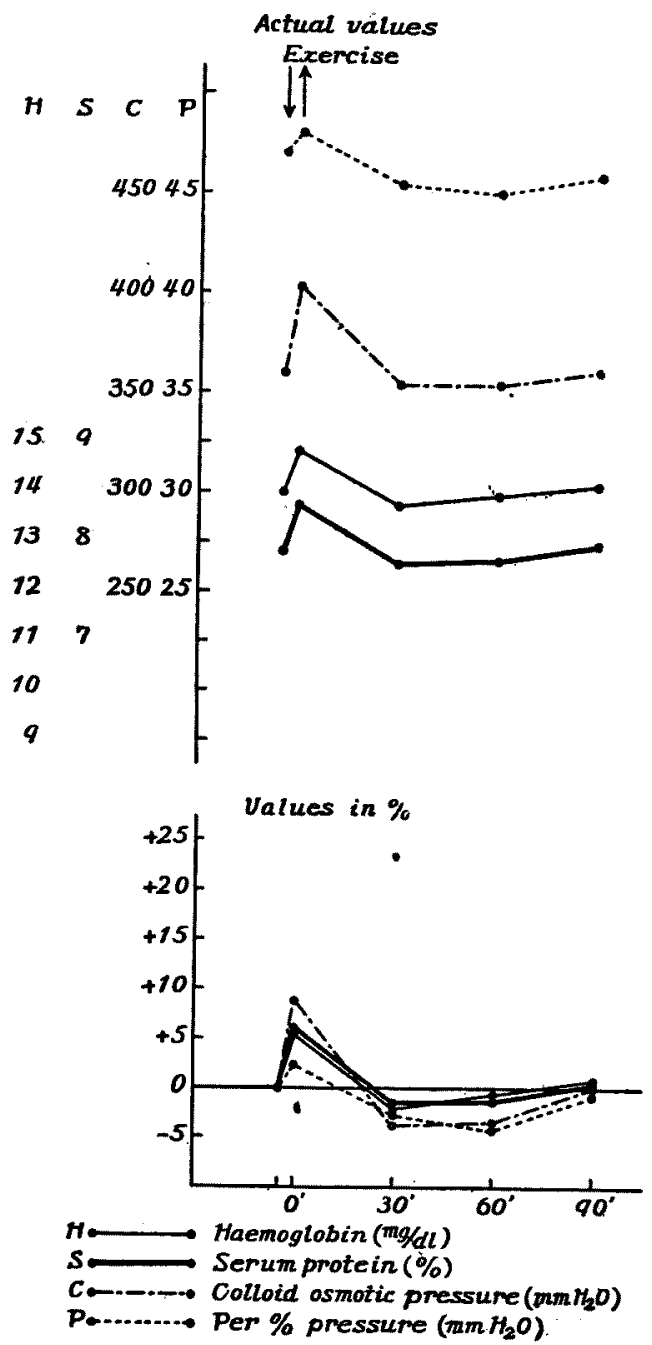

mediately after muscular exercise is greater than that of control experiments, being $+6.4 \sim+14 \%$ of the original values. Though the individual fluctuation is remarkable, it may be said that in the majority of the cases the ratio of increase is less than that of protein, or the haemoglobin content shows a marked diminution when the blood protein changes little. But there are some cases, in which the ratio of increase of haemoglobin immediately after muscular exercise is greater than that of protein ( 3 cases), in another one case the same is noticed in the later stage.

Blood protein: Blood protein content increases immediately after 
Fig. 2. 5 case of malnutrition.

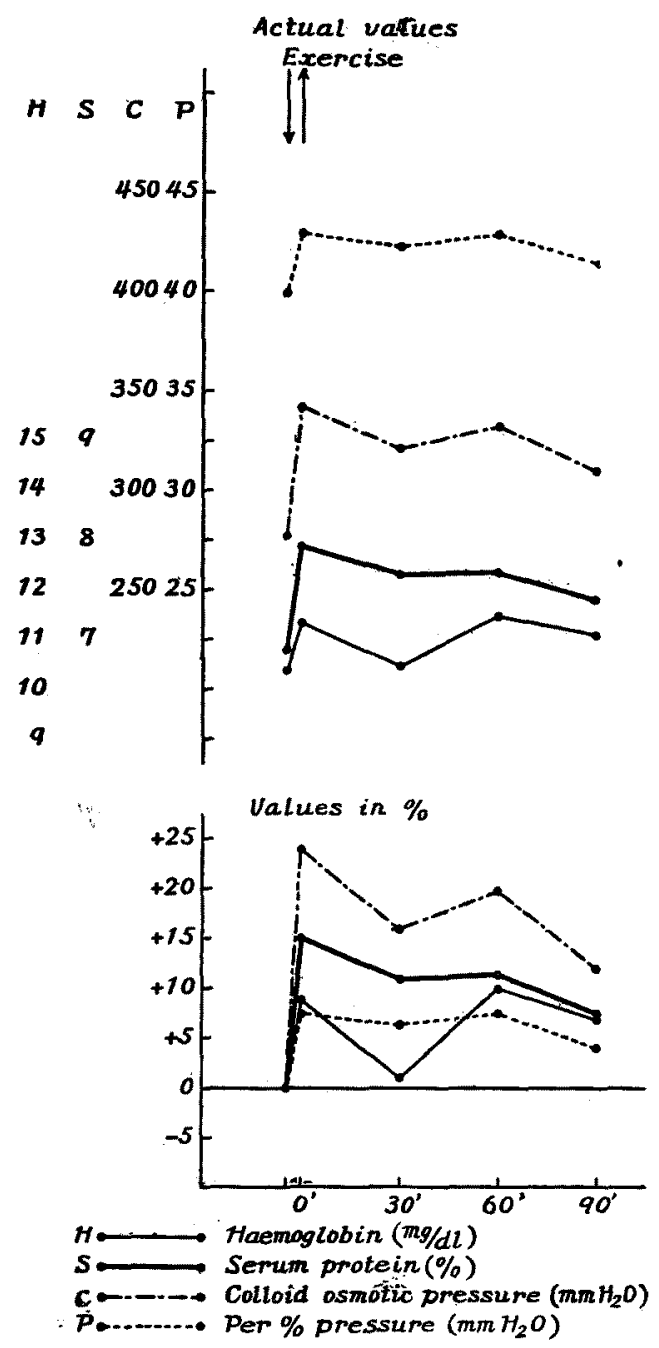

muscular exercise in a range of $10 \%$ to $16 \%$, is afterward gradually lessened, but without returning to the original value within 30 minutes as this is the case in healthy subject. In some instances ( 3 cases), it is augmented to the maximum after 30 or 60 minutes, then being reduced afterward. In general, the recovery of the increased pratein concentration to the initial level is delayed, in 6 cases it takes more than 90 minutes.

Colloid osmotic pressure of the blood: The increase of colloid osmotic pressure of blood after muscular exercise is very marked, its ratio being $15 \% \sim 20 \%$ of the original value. In one case it reaches $80 \%$ above the 
initial value immediately after the muscular exercise. But even in this case the absolute value of increased colloid osmotic pressure does not surpass $400 \mathrm{~mm} \mathrm{H}_{2} \mathrm{O}$, thus remaining within the mean value $\left(403 \mathrm{~mm} \mathrm{H}_{2} \mathrm{O}\right.$ ) of healthy subject in the same phase. In one case a slight increase could be seen again after 60 minutes. On the whole the increased values do not recover within 90 minutes.

Per $\%$ pressure: The per $\%$ pressure of blood protein rises immediately after the muscular exercise also strikingly $(2.2 \% \sim 65 \%)$ : In 6 cases it didn't return to the initial value within 90 minutes.

\section{Discussion and Summary.}

In present investigation it has been demonstrated, that in malnutrition the blood protein, especially albumin concentration increases markedly by muscular exercise. It is necessary to explain the mechanisms of changes in blood protein after muscular exercise in healthy man, before we consider it in patient with malnutrition. Miyamoto ${ }^{211}$ attached importance to the changes of blood $\mathrm{pH}$ as the cause of increase of blood protein, especially that of albumin by muscular exercise. Nishiyama, ${ }^{20)}$ on the other hand, took a possibility into account that the function of blood protein regulating organs may not be enough to act in accomodation with a burden, which is suddenly charged on. Endo ${ }^{22}$ suggested under the acidotic condition the blood globulin tends to increase while the blood albumin decreases. Kasugai23) and Miura ${ }^{24)}$ observed the same tendency in blood protein in case of oxygen deficiency. According to these investigators the change of blood $\mathrm{pH}$, namely the increase of hydrogen ion concentration in the blood after muscular exercise will cause the reverse in the ratio of albumin to globulin in blood, so that we cannot help to think that the changes in blood protein pointed out in the present investigation are apparently due to other factor than blood $\mathrm{pH}$.

As related above, Endo confirmed that albumin comes out of the skeletal muscules in considerable amount during their contraction. On the other hand, the function of blood protein regulating organs, particularly of liver is regarded as to house blood albumin in themselves and to discharge globulin into blood. Therefore, as soon as a lot of albumin are released from muscles by contraction into blood, the blood protein regulating organs will strive to house these albumins in themselves, so as to keep the colloid osmotic pressure of the blood constant. The facts observed in present experiments that the colloid osmotic pressure per $\%$ protein reduced temporarily in the time interval of 30 to 60 minutes after the ended muscular exercise suggests that albumin diminishes and globulin increases relatively during this phase. This is apparently because the 
exaggerated function of those blood protein regulating organs survives for a time, thus, after the muscles cease to release albumin, the latter is taken into the regulating organs completely, even so excessively that albumin diminishes under the original level, and on the other hand globulin increases relatively. When the exaggerated function recovers successively, the changed blood protein returns to the original value. Thus, the changes in blood protein by muscular exercise are caused by two functions, one being the release of fine disperse protein particles of albumin class from muscles into blood, the other the intake of those released albumins into the liver and other regulating organs and the discharge from the latter of large protein particles of globulin class into the blood. Considering from this point of view the case in malnutrition, it may be pointed out, first of all, that in this deficient nutritional condition severe changes in the blood protein regulating organs are confirmed by autopsy, ${ }^{11}$ especially atrophy and degeneration of liver cells, also oedematous dilatation of Disse's cavity in this organ, similar to that in case of pepton shock. It is ascertained, that those changes belonging to serous inflammation can also be seen in other organs. In this disease, therefore, as a result of the deficient supply of protein and the insufficient blood protein regulating function of liver and other organs caused by it the blood protein, especially its albumin fraction is reduced, while globulin fraction uses to stay unchanged or rather slightly increases, thus causing so called shift to the left in the protein picture. If the loading of muscular exercise is forced on the patient, those organs, due to the impairment of their protein regulating function, can not only house the protein of albumin class completely in themselves, but also will discharge even the stored one in a vast quantity from them into the blood.

In malnutrition, it is ascertained that creatin output in urine is increased, suggesting the existence of some abnormal protein metabolism in muscles. ${ }^{25)}$ Yoshimura ${ }^{26)}$ observed output of phosphoric acid is also exaggerated especially remarkably after muscular exercise. These facts indicate abnormal metabolism in muscular tissues during the muscular exercise, by which albumin particles in a great amount are released from muscles into the blood stream, whilst the functional insufficiency of the . blood protein regulating organs causes incomplete housing of them, thus giving rise to such a remarkable increase of blood protein, especially that of albumin class, as was related above.

In present experiments it has been pointed out, that the changes in blood concentration by muscular exercise show an interesting course. In malnutrition the autopsy ${ }^{1)}$ suggests the existence of serous inflammation in vascular capillaries all over the body, and in severe cases leakage of red blood cells through the capillary walls. Maase ${ }^{27)}$ attributed the essential 
cause of hunger oedema to the augmented permeability and injured water resorbence of capillary walls. Hatafuku ${ }^{28)}$ found in fasting increased affinity of tissues to water. In healthy person also, after the muscular exercise blood water transfers into tissues, giving rise to temporary blood concentrating. Acidosis due to muscular exercise causes rise of oncotic pressure of the tissues ${ }^{29}$ ) and increased permeability of capillary walls followed by transfer of blood water into the tissues. ${ }^{30-31}$ In malnutrition the blood reaction is inclined to acidosis and the lactic acid content of blood is augmented. Kajiwara ${ }^{32}$ ) observed that the blood lactic acid level is elevated remarkably after muscular exercise. He has estimated in our Laboratory the lactic acid content of blood in the same patient under the same condition as in the present investigation at rest and after muscular exercise and found its remarkable increase and delayed recovery after exercise in comparison with healthy person. Thus, it is beyond doubt, that in malnutrition above mentioned factors give rise to the marked increase of blood concentration after muscular exercise.

There could be observed two types of the changes in blood concentration in the course after the muscular exercise. In one type the blood remains concentrated relatively long time ( 6 cases) and in the another type the concentration of the blood is followed by intensive dilution ( 6 cases). The first type is seen in the experiments performed in cold season, and the second in ones performed in hot season. Among the clinical symptoms of our examinees oedema is intensive in summer and slight in winter. The first type may presumably be due simply to continued acidosis. As to the second type on the other hand, there is a marked tendency to oedema with a lot of tissue fluid between tissue cells and during the muscular exercise tissue cells take water from this tissue fluid for a while, the blood water begins to participate later in this water movement, when the transfer of water from tissue fluid reaches to some extent. Hence in this type the concentration of blood is less intense than in the other type, in the following stadium a vast quantity of water from tissue fluid comes into the capillaries causing an intense blood dilution.

In present experiments it is sometimes noticed that the ratio of increase of blood concentration after muscular exercise is greater than that of blood protein, a fact which is not obersved in healthy person. It is perhaps because a great amount of blood water goes out rapidly through capillary walls.

\section{Conclusrons.}

In present study, in which the changes in the blood protein and blood concentration by muscular exercise in malnutrition patients and healthy persons were investigated, it has been ascertained that there is an abnor- 
mality in intermediate blood protein metabolism in malnutrition, as follows.

(1) In healthy man the blood protein, especially that of albumin class, increases temporarily immediately after muscular exercise, but is reduced soon afterward under the original value, whereby again the diminution of albumin particles is predominant.

(2) In malnutrition the increase of protein, especially that of albumin class, by muscular exercise is remarkably exaggerated, compared with that in healthy person and the recovery to the original value is apparently delayed. Those changes indicate the discharge of albumin particles in a vast quantity from muscular tissues into the blood during their contraction on one hand, and the latent insufficiency of the blood protein regulating organs such as liver, on the other hand, which cannot house the protein particles fully in themselves, especially of albumin class. It is suggested that in malnutrition there is some functional disturbance in the blood protein regulating organs.

(3) It is also confirmed by the experiments with loading of muscular exercise, that this disease manifests remarkable functional changes in the capillary walls for water metabolism. This is obvious from the fact that intense concentration of blood immediately after muscular exercise is often observed and that following on it a marked blood dilution may come on due to immense water transsudation from tissue into capillaries.

\section{References.}

1) Takizawa, Nichibei Igaku, 1947, 1, 151.

2) Fuse, Sogo Igaku, 1946, 3, 340 .

3) Horikawa, Tohoku J. Exp. Med., 1936, 28, 90 Ư 215.

4) Yasuda, ibid., 1937, 31, 430.

5) Shida, ibid., 1939, 35, 304.

6) Kusano, ibid., 1938, 34, 246.

7) Endo, ibid., 1944, 48, 25.

8) Hatafuku, ibid., 1933, 21, 226.

9) Shibuya, ibid., 1938, 34, 571.

10) Fillinski, Wien. klin. Wschr., 1925, 1110.

11) Ozawa, Hukuoka Igakaigaku Zasshi, 1926, 19, 701.

12) Sanada, Zikken Igaku Zasshi, 1927-28, 2, 242.

13) Tanaka, Hukuoka Ikadaigaku Zasshi, 1928, 21, 1948.

14) Starling and Winands, Ztschr. ges. exp. Med., 1928, 138, 60.

15) Shibuya, Igaku Kenkyu, 1931, 5, 325.

16) Nakazawa, Nihon Naikagaku Zasshi, 1943, 31, 311.

17) Osato, Nihon Rinsho, 1946, 4, 708.

18) Miura, Tohoku J. Exp. Med., 1936, 30, 16.

19) Hayakawa:, Koku Igaku Zasshi, 1940, 1, 302.

20) Nishiyama, Tohoku J. Exp. Med., 1934, 22, 541.

21) Miyamoto and Sugimoto, ibid., 1934, 24, 238. 
22) Endo, ibid,, 1944, 47, 236.

23) Kasugai, ibid., 1935, 27, $478 \& 505$.

24) Miura, ibid., 1936, 30, 49.

25) Takahashi, Igaku To Seibutsugaku, 1947, 11, 211.

26) Yoshimura, Igaku To Minsei, 1946, 1, 2.

27) Maase, Das Hungeroedem. Leipzig 1920.

28) Hatahuku, Tohoku J. Exp. Med., 1933, 21, 13.

29) Russel, Moore, Fletcher, Körper u. Arbeit. Leipzig 1927.

30) Barcroft and Kato, Philos. Transact. Roy. Soc. Lond. B 1915, 27, 149. Proc. Roy. Soc. B. $1915,88,541$.

31) Landis, Amer. Jour. Physiol., 1927-28, 83, 528.

32) Kajiwara, Iryo, 1948, 2, 26. 